\title{
A INSUFICIÊNCIA DA RESPONSABILIDADE SOCIOAMBIENTAL EMPRESARIAL NA PERSPECTIVA DO DESENVOLVIMENTO SUSTENTÁVEL
}

\section{THE INSUFFICIENCY OF THE SOCIAL AND ENVIRONMENTAL CORPORATE RESPONSIBILITY IN SUSTAINABLE DEVELOPMENT PERSPECTIVE}

Recebido: 10.08 .2017

Aprovado: 04.09.2017

\author{
Jacopo Paffarini* \\ Mariângela Matarazzo Fanfa Colognese** \\ Eduardo Henrique Hamel ${ }^{* * *}$
}

RESUMO: O desenvolvimento econômico fundamentado na exploração desenfreada da natureza é uma sistemática funcional para os objetivos do capitalismo. Diante dos problemas ambientais decorrentes das atividades econômicas e industriais, o mundo corporativo despertou para a necessidade de incorporar a questão socioambiental na gestão. Todavia, persiste a incompatibilidade entre as finalidades do capitalismo e o desenvolvimento sustentável. A responsabilidade socioambiental corporativa nãoatingiu níveis razoáveis de efetividade e luta para conciliar o sistema produtivista e consumista com a preservação ambiental. Este estudo tem como objetivo questionar a insuficiência da responsabilidade socioambiental empresarial na perspectiva do desenvolvimento sustentável e promover a Sociologia Ambiental como ferramenta de conscientização. Nesse contexto, surge como imprescindível a abordagem do desenvolvimento na sujeição da sustentabilidade, a partir de outra perspectiva frente às ações e práticas de produção que ajustam o desenvolvimento. Através de pesquisa exploratória bibliográfica, são descritos esses conceitos e suas aproximações e afastamentos. Conclui-se que o esgotamento ambiental é um limite para o avanço do capitalismo e gerenciar essa crise planetária pressupõe a aprendizagem focada na consciência ambiental e na construção social ambiental.

\footnotetext{
* Doutor em Direito Público pela Università degli Studi di Perugia (Itália). Pós-Doutor em Direito - Faculdade Meridional (Brasil). Professor Permanente no Programa de Pós-Graduação Stricto Sensu em Direito, Faculdade Meridional - IMED. Bacharel em Direito pela Università degli Studi di Perugia. Pesquisador Visitante do Instituto Max-Planck de Direito Público Comparado - Heidelberg (Alemanha). Membro pesquisador do Grupo Internacional de Pesquisa Rights behind Bars in Europe, financiado pelo Ministério de Instrução, das Universidades e Pesquisa (Decreto Direttoriale, 25 giugno 2015 n. 1350). Colaborador assistente na Cátedra de Direito Constitucional e Direito Público Comparado, de titularidade do Prof. Dr. Maurizio Oliviero, junto ao Curso de Direito da Università degli Studi di Perugia. Co-orientador do módulo de Direito Transnacional no curso de Direito Público Comparado. E-mail: < jacopo.paffarini@imed.edu.br >.

** Mestre em Direito, Democracia e Sustentabilidade pelo Programa de Pós-Graduação do Complexo de Ensino Superior Meridional - IMED/Passo Fundo, RS. Pesquisadora no Grupo de Pesquisa "Jurisdição e Democracia" e "Ética, Cidadania e Sustentabilidade” do Programa de Pós-Graduação Stricto Sensu em Direito - IMED/RS. E-mail:< mari. colognese@gmail.com >.

*** Mestre em Direito pelo Programa de Pós-Graduação do Complexo de Ensino Superior Meridional - IMED/Passo Fundo, RS. Professor do Curso de Direito da Faculdade IDEAU, Campus Getúlio Vargas, RS. E-mail: < duduhip@bol. com.br $>$.
} 
Palavras-chave: Capitalismo. Desenvolvimento sustentável. Dano ambiental. Responsabilidade. Sociologia ambiental.

\begin{abstract}
The economic development based on the unbridled exploitation of nature is a functional systematic for the purposes of capitalism. Faced with the environmental problems arising from economic and industrial activities, the corporate world has awakened to the need to incorporate social and environmental issues in management. However, persists the incompatibility between capitalism and sustainable development purposes. Therefore, the corporate social and environmental responsibility has not reached reasonable levels of effectivness and it struggles to reconcile productivist and consumerist system with environmental preservation. This study aims to question the insufficiency of corporate social-environmental responsibility in the perspective of sustainable development and to promote Environmental Sociology as an awareness tool. In this context, the approach of development in the subjection of sustainability emerged as essential, from another perspective regarding the actions and production practices that adjust the development. Through exploratory bibliographic research, these concepts and their approximations and departures are described. It is concluded that environmental depletion is a limit for the advance of capitalism and managing this planetary crisis presupposes learning focused on environmental awareness and environmental social construction.
\end{abstract}

Keywords: Capitalism. Sustainable development. Environmental harm. Responsibility. Environmental sociology.

\title{
INTRODUÇÃO
}

O século XX foi a era do expansionismo da produção industrial. A pretexto do desenvolvimento, grandes quantidades de recursos naturais passaram a ser utilizados por pessoas e empresas para atingir as metas impostas pelo capitalismo, modelo econômico que se consolidou no mundo inteiro a partir da segunda Revolução Industrial. Profundas transformações ocorreram não só na área da produção com a substituição do trabalho humano pelas máquinas e a utilização intensiva de energia. A exploração de recursos naturais causou a instabilidade ambiental e a desorganização ecológica, com a ocorrência de danos ambientais em grande escala.

Em 1987, a Comissão Mundial sobre Meio Ambiente e Desenvolvimento publicou o Relatório Brundtland, projetando os problemas globais do meio ambiente e do desenvolvimento e trazendo o conceito de desenvolvimento sustentável para o debate público como crítica ao crescimento econômico fundamentado na exploração desenfreada da natureza.

As consequências da desorganização ambiental começaram a se propalar rapidamente e exigiram que o mundo corporativo incorporasse a questão socioambiental na gestão. Todavia, persiste a incompatibilidade entre as finalidades do capitalismo e o desenvolvimento sustentável. Estudos indicam que os níveis de risco aumentaram, assim 
como os danos perpetrados por corporações, com graves violações aos direitos humanos, mesmo com a legislação mais rígida em termos de responsabilidade civil e criminal. Ainda que muitas empresas estejam preocupadas em minimizar o impacto de suas atividades, muitas outras as mascaram. O Estado atua tanto de forma comissiva como omissiva em relação aos atos lesivos contra o meio ambiente, pois permite a instalação de empresas cujas atividades são prejudiciais à natureza ou adota políticas nocivas a este.

Esses processos decorrem da uma política comum de algumas grandes corporações que criaram o seu próprio direito em detrimento das leis estaduais. Diante deste mercado "autorregulado", a sustentabilidade foi questionada com a crise de 20072008, contudo, as tendências expostas não se inverteram. Os Estados-Membros ainda carecem de meios para evitar as principais práticas perigosas que caracterizaram o “capitalismo predatório”. Essa situação se mantém, primeiramente, pelas contradições do próprio sistema capitalista. Em segundo lugar, as desigualdades não são apenas as consequências diretas do atual mecanismo de acumulação de capital, mas o reflexo dos arranjos jurídicos consolidados anteriormente.

Nos últimos tempos, especialistas internacionais recomendaram uma regulamentação financeira eficaz como um ponto-chave para enfrentar abusos sistemáticos. Essas práticas têm encontrado legitimidade desde o PIB, que tem sido usado como uma medida de bem estar das nações, não apenas de desempenho das empresas. Assim, preservar os direitos humanos e o crescimento sustentável começa com o resgate de economistas e políticas governamentais dos parâmetros enganadores que cultivaram o "fetichismo do PIB".

As últimas conferências internacionais encararam questões urgentes, dialogando a "reforma do capitalismo", reconhecendo que a luta contra as desigualdades não tem apresentado resultados efetivos, do mesmo modo que combater as alterações climáticas não se limitará às "bio-tecnologias" ou "energias verdes". O lucro rápido e ilimitado impede o planejamento industrial e inibe a inovação sobre expedientes sustentáveis.

Em razão de circunstâncias como operações de greenwashing, fiscalização inadequada, poluição e destruição do meio ambiente e de comunidades afetadas por grandes projetos, etambéminfluênciaindevidadefinanciamentosprivadosdecampanhas eleitorais nos processos regulatórios do governo, a responsabilidade socioambiental empresarial se mostra insuficiente para conciliar um sistema produtivista/consumista e político/economicista com a preservação ambiental.

Diante disso, remanesce a seguinte problemática: iniciativas socioambientais corporativas são suficientes para equalizar a relação entre capitalismo e desenvolvimento sustentável? Para responderessa indagação, questionara insuficiênciada responsabilidade socioambiental empresarial na perspectiva do desenvolvimento sustentável e promover a Sociologia Ambiental como ferramenta de conscientização são os objetivos centrais deste estudo. Através de pesquisa exploratória bibliográfica, são descritos esses conceitos e suas aproximações e afastamentos para vislumbrar possíveis alternativas à problemática ambiental. 


\section{A INCOMPATIBILIDADE ENTRE CONSERVAÇÃO AMBIENTAL E DESENVOLVIMENTO ECONÔMICO}

O século XX foi marcado pela consolidação do capitalismo industrial como modo de produção. Através deste sistema, a pretexto do desenvolvimento, as pessoas, sobretudo empresas, têm utilizado grandes quantidades de recursos naturais, causando a instabilidade ambiental e a desorganização ecológica. Consequentemente, danos ambientais em grande escala tem ocorrido.

A urgência ambiental exigiu a adequação a uma nova realidade. Nas últimas décadas uma atenção sem precedentes foi projetada na conscientização de que a degradação ambiental poderia efetivamente ameaçar a sobrevivência de todas as formas de vida no planeta.

A raiz do Direito Ambiental se fixa a partir da publicação do relatório "Os limites do crescimento", em 1972, pelo Clube de Roma, cujo objetivo era fomentar um debate global sobre o meio ambiente e o desenvolvimento sustentável. No relatório, problemas como energia, poluição, saneamento, saúde, ambiente, tecnologia e crescimento populacional informam a preocupação com o futuro da humanidade (ARMADA; VIEIRA, 2014).

A publicação influenciou a realização da Conferência das Nações Unidas sobre o Meio Ambiente Humano, em Estocolmo, no ano de 1972, a qual inaugurou a agenda ambiental internacional fixando um novo modelo para a economia e para o conceito de desenvolvimento (ARMADA; VIEIRA, 2014). Na oportunidade foi criada a Comissão Mundial sobre Meio Ambiente e Desenvolvimento (World Commission on Environment and Development).

Em abril de 1987, a Comissão Mundial sobre Meio Ambiente e Desenvolvimento publicou o Relatório Brundtland, "Nosso Futuro Comum" (Our Common Future), preocupado em projetar os problemas globais do meio ambiente e do desenvolvimento, trouxe o conceito de desenvolvimento sustentável para estimular uma responsabilidade coletiva e orientar as ações de todas as nações no atendimento das necessidades do presente sem comprometer o aporte às gerações futuras (ONU, 1987). Este conceito encerra não só o modelo de crescimento socioeconômico e de justiça social ideal, mas a crítica ao desenvolvimento econômico fundamentado na exploração desenfreada da natureza pelos países industrializados e também pelas nações em desenvolvimento. Essas e outras recomendações culminaram com a Conferência das Nações Unidas sobre o Meio Ambiente e o Desenvolvimento, realizada no Rio de Janeiro, em 1992, onde a necessidade imperativa de um desenvolvimento sustentável foi reconhecida de forma definitiva no debate público mundial.

O Relatório Brundtland, como paradigma do desenvolvimento sustentável, expôs a (i)lógica do mercado e o tratamento do meio ambiente, exigindo uma transformação dos modelos corporativos ao ressaltar que "a ecologia e a economia estão cada vez mais entrelaçadas-emâmbitolocal, regional, nacional emundial-numaredeinteiriça decausas e efeitos" (COMISSÃO MUNDIAL SOBRE MEIO AMBIENTE E DESENVOLVIMENTO, 1991, p. 5). Ainda que se afirme esse "entrelaçamento", ele constitui um paradoxo: o capitalismo e a natureza não caminham de mãos dadas. 
Esse processo decorre da uma política comum de algumas grandes corporações, que preferiram criar "o seu próprio direito", em detrimento das leis estaduais. A "Lex Mercatoria", as câmaras de arbitragem das diferentes áreas do mundo e os princípios da Unidroit são alguns dos exemplos mais conhecidos do que foi chamado de "um conceito transnacional de Direito" (GLENN, 2005, p. 840). A crise de 2007-2008 questionou severamente a sustentabilidade de um mercado "autorregulado", mas não inverteu as tendências expostas. As autoridades dos Estados-Membros ainda alegam a falta de meios para evitar as principais práticas perigosas que caracterizaram o desenvolvimento de um "capitalismo predatório" até os dias atuais.

A manutenção dessa situação, apesar das evidências de abusos contínuos em detrimento dos bens comuns, encontra duas razões principais. A primeira, como reafirmadorecentemente, osistemacapitalista nãopodeexistirsemalgumas “contradições fundamentais", assim, as crises são endêmicas, pois representam "momentos de transformação em que o capital tipicamente se reinventa e se transforma em outra coisa" (HARVEY, 2015, p. 4). Algumas dinâmicas de acumulação de capital incentivam claramente as infrações legais, especialmente por diretores executivos (CEO), aos quais os acionistas da empresa frequentemente oferecem uma renda extra para promover seus próprios interesses. A maximização do lucro dos principais acionistas, bem como a responsabilidade limitada corporativa promovem uma "economia faccionista" (factionist economy) dentro da qual o interesse comum e os demais interesses das partes interessadas (funcionários, consumidores, pequenos acionistas) representam um objetivo menor. A crise de 2007-2008 revelou (novamente) como os conflitos de interesses dentro da governança corporativa podem minar a sobrevivência da empresa e o equilíbrio do mercado, ao mesmo tempo em que proporcionam enormes lucros a esses gestores e proprietários desprovidos de freios éticos.

A maximização de uma coisa implica necessariamente o empobrecimento de tudo o mais, com um foco resultante no curto prazo imediato. A importância decisiva da maximização foi alcançada pela sua conversão da maximização de lucros, que era potencialmente pelo menos para benefício de todos os stakeholders da empresa, para maximizar a riqueza dos acionistas. Isto foi primeiramente enunciado por Milton Friedman em 1962, como sendo a única responsabilidade social dos oficiais incorporados. O resultado foi o empobrecimento de outras partes interessadas ea priorização do curto prazo sobre os interesses a longo prazo ${ }^{2}$. (CORPORATE REFORM COLLECTIVE, 2014, p. 47-48).

Em segundo lugar, as desigualdades não são apenas as consequências diretas

\footnotetext{
1 Entre as mais recentes contribuições sobre o tema, ver CORPORATE REFORM COLLECTIVE. Fighting corporate abuse. Beyond predatory capitalism. London: Pluto Press, 2014.

2 "Maximization of one thing necessarily implies the impoverishment of everything else, with a resulting focus on the immediate short term. The decisive importance of maximization was achieved by its conversion from maximizing profits, which was potentially at least for the benefit of all company stakeholders, to maximizing shareholder wealth. This was first enunciated by Milton Friedman in 1962, as being the only social responsibility of corporate officials. The result has been the impoverishment of other stakeholders and the prioritizing of the short-term over the longer-term interests". (Tradução nossa) Consultar também as referências ali citadas, como FRIEDMAN, Milton. Capitalism and Freedom. Chicago: Chicago University Press, 1962.
} 
do atual mecanismo de acumulação de capital, mas o reflexo dos arranjos jurídicos consolidados nas fases anteriores de seu desenvolvimento. Os contribuintes sempre suportaram o reequilíbrio após as perdas financeiras. O que mudou depois de 2008, no entanto, é a magnitude da quebra do sistema devido à nova potencialidade da economia financeira após o fim do Golden Exchange Standard. Como observou David Harvey (2015, tradução nossa)3:

Quando o dinheiro era limitado por estar ancorado, ainda que fracamente, na disponibilidade material e na escassez relativa das mercadorias monetárias físicas, então havia uma restrição material à criação infinita do dinheiro. $\mathrm{O}$ abandono da base metálica da oferta monetária mundial no início dos anos 70 criou um novo mundo de possíveis contradições. O dinheiro poderia ser impresso ad infinitum por quem está autorizado a fazê-lo. A oferta monetária estava nas mãos de instituições humanas falíveis, como os bancos centrais. (HARVEY, 2015, p. 37).

Enquanto economistas e jornais repetem o mantra "too big to fail" (muito grande para falir) para justificar o enorme sequestro de dinheiro público para "resgatar" os bancos em crise, a mesma "falsa teoria econômica" está influenciando a abordagem dos tribunais aos abusos corporativos, providenciando a impunidade para seus diretores e principais acionistas 4 .

A corrida global para o crescimento do PIB criou uma competição entre as políticas governamentais, que minimiza os custos humanos e ambientais de uma acumulação capitalista infinita. Nos últimos tempos, especialistas internacionais finalmente recomendaram uma regulamentação financeira eficaz como um ponto chave para enfrentar abusos sistemáticos cometidos por diretores inescrupulosos. Não deve ser oculto que essas práticas têm encontrado legitimidade desde o PIB, que tem sido usado como uma medida de bem estar das nações, não apenas de desempenho das empresas. Em relação a esse "bem estar", o economista indiano, Amartya Sen (2010), estabelece uma forma diferente de contemplar a riqueza e o desenvolvimento: em lugar de vê-los por si mesmos unicamente, eles são como meios poderosos para alcançar a felicidade, ou o mais próximo a ela, como poderia ser viver por muito tempo e em ótimas condições de bem estar e liberdade (SEN, 2010). A partir desse ponto de vista, o desenvolvimento não é um fim em si mesmo, mas um meio para se chegar a uma meta, com a influência muito complexa de outros fatores, especialmente as liberdades políticas e civis, que "são elementos constitutivos da liberdade humana, sua negação é, em si, uma deficiência" (SEN, 2010, p. 31). Em síntese, a abordagem de Amartya Sen ressalta que é insuficiente basear-nos no estudo das receitas pessoais para saber o estado de felicidade de uma pessoa ou uma comunidade ${ }^{5}$, pois estas contrastam com as perspectivas restritas do desenvolvimento

\footnotetext{
3 "When money was constrained by being anchored, however weakly, in the material availability and relative scarcity of the physical money commodities, then there was a material restraint upon the infinite creation of money. The abandonment of the metallic base of the world's money supply in the early 1970's created a whole new world of possible contradictions. Money could be printed ad infinitum by whoever is authorised to do so. The money supply lay in the hands of fallible human institutions such as the central banks". (Tradução nossa)
}

$4 \mathrm{O}$ argumento de maximizar a riqueza dos acionistas na expansão de todos os outros atores não tem apoio jurídico nem teórico. No entanto, agir contra os interesses da empresa para o ganho exclusivo dos accionistas ainda não foi testado nos tribunais como uma ofensa criminal (CORPORATE REFORM COLLECTIVE, 2014, p. 49, tradução nossa).

5 Para poder conceber um aumento de bem estar como proposto é necessário não tomar como seu indicador a renda auferida pelos indivíduos e sim a capacidade de cada um para transformá-la em seu próprio proveito, por exemplo, um 
(crescimento do produto interno bruto, aumento de renda pessoal, industrialização, progresso tecnológico, modernização social etc.).

Assim, preservar os direitos humanos e o crescimento sustentável começa com o resgate de economistas e políticas governamentais dos parâmetros enganadores que cultivaram o "fetichismo do PIB". Isso significaria um controle sobre a criação de dinheiro dos bancos comerciais, ou seja, impedir qualquer acesso discricionário ao crédito que não esteja de acordo com os objetivos políticos globais (e não apenas econômicos).

As últimas conferências internacionais, pelas quais o renascimento do "populismo político" encara uma questão urgente, finalmente apoiaram um diálogo aberto para a "reforma do capitalismo", reconhecendo uma escassez de resultados efetivos na luta contra as desigualdades de riqueza. $\mathrm{Na}$ frente paralela, no que se refere às alterações climáticas, tem-se considerado que a resposta não se limitará à "logística" da produção industrial - como as "biotecnologias" ou "energias verdes". Isso porque os "ganhos rápidos" da atual fase do capitalismo, provenientes das injeções de créditos de curto prazo, impedem o planejamento industrial e inibem a inovação sobre expedientes sustentáveis para a produção de commodities. De acordo com David Harvey (2015, p. 252, tradução nossa), “o capital não pode, infelizmente, mudar a forma como corta e transforma a natureza em forma de mercadorias e direitos de propriedade privada".

Por isso, foi observado que muito mais na redução das emissões de $\mathrm{CO} 2$ poderia ser feito se "a responsabilidade pela criação de dinheiro fosse colocada com uma agência independente que - diferentemente de nossos bancos - fosse democrática, responsável e transparente, de modo que o dinheiro se tornasse um bem verdadeiramente público" (HICKEL, 2016).

Esses são fatos que podem ser atribuídos à própria finalidade do capitalismo, que é a maximização do lucro, a exploração do trabalho, o aumento da taxa de produção, a redução dos custos, o aumento das vendas (MARX, 1996). Para que essas metas sejam atingidas, deve-se, portanto, utilizar inumeráveis recursos naturais. Inevitavelmente disso resultará a destruição do ecossistema. Em relação à análise das maneiras como o capitalismo destrói a natureza e o exame das consequências ecológicas negativas desenvolveu-se a teoria da esteira de produção (treadmill of production). Esse conceito foi introduzido por Allan Schnaiberg em seu livro "The Environment: From Surplus to Scarcity" (1980). É uma abordagem econômica política para a compreensão da desorganização ambiental ecológica, da destruição ambiental e dos danos na era pósSegunda Guerra Mundial, além de um grande contributo para o tema de uma dialética socioambiental. O centro da teoria da esteira de produção é a ideia de que o capitalismo é um meio de produção ecologicamente destrutivo e que os processos de produção e consumo de bens geram desorganização ecológica ${ }^{7}$

deficiente necessita de uma renda maior para disfrutar de um mesmo bem estar que uma pessoa fisicamente saudável. Para Sen (2010), está correto o pensamento de que não se deve medir o desenvolvimento com base na renda, senão pela capacidade das pessoas de transformarem essa renda naquilo que consideram necessário para viver como desejam.

6 "The responsibility for money creation would be placed with an independent agency that - unlike our banks would be democratic, accountable, and transparent, so money would become a truly public good" (Tradução nossa).

7 Schnaiberg se afasta do reducionismo econômico e analisa como certos projetos de "capitalismo político" encorajavam a degradação ambiental. As tendências ecologicamente destrutivas do capitalismo são observadas nos 
A teoria de Schnaiberg também chama a atenção para as maneiras pelas quais o Estado, o setor privado e o trabalho interagem para facilitar a desorganização ecológica. Schnaiberg (1980) argumentou que cada um desses setores se interessa por aumentála para seu próprio benefício. Em suma, a teoria da esteira de produção explica como a organização econômica política do capitalismo e as inovações químicas/tecnológicas na esteira de produção capitalista pós-Segunda Guerra Mundial aceleram a degradação ambiental.

A substituição do trabalho humano pelas máquinas e a utilização intensiva de energia resulta uma grande quantidade de poluentes. A extração de gases naturais, petróleo e minérios causam mudanças nas paisagens naturais, poluição do ar e das águas, mudanças climáticas e o decréscimo de áreas verdes e diversidade de animais (BUDÓ et al. 2016). Tudo em nome da potencialização do lucro e do consumo. E como resultado, desde a década de 70, a cada ano dobra o número de pessoas atingidas por catástrofes "naturais". As secas e as inundações são as catástrofes mais diretamente ligadas à má administração do meio ambiente e do desenvolvimento, afetaram o maior número de pessoas e intensificaram drasticamente o número de vítimas (COMISSÃO MUNDIAL SOBRE MEIO AMBIENTE E DESENVOLVIMENTO, 1991). Esses dados constam no Relatório Brundtland, mas os números atuais apontam para mais de 226 milhões de pessoas afetadas por desastres a cada ano. Entre 2002 e 2011 foram registrados 4.130 desastres naturais no mundo, nos quais mais de 1 milhão de pessoas morreram e um mínimo de 1 trilhão de dólares foi contabilizado em perdas financeiras. O risco de se perder riquezas em desastres está superando a capacidade de criação de riquezas (ONU, 2012).

O enfrentamento do risco dos desastres naturais como terremotos, inundações, secas, furacões e tsunamis e seus impactos devastadores sobre as pessoas, o meio ambiente e as economias é um dos grandes desafios para o desenvolvimento sustentável. A ONU (2012) alerta que "os níveis de risco estão aumentando em razão de fatores como as alterações climáticas, a pobreza, as falhas de planejamento e gestão no ordenamento territorial e a degradação dos ecossistemas”. Desse modo, não há dificuldade em demonstrar que os problemas ambientais são frequentemente associados ao modelo capitalista e ao padrão de atividade econômica e industrial. Pesquisadores ecológicos, ambientalistas, criminologistas verdes, sociólogos, todos oferecem argumentos que ligam a industrialização, a urbanização e a modernização à desorganização ecológica.

processos de retiradas ecológicas e adições ecológicas. As retiradas ecológicas são definidas como danos ao recurso que o capitalismo produz no processo de extração de matérias-primas. Na era da pós-Segunda Guerra Mundial, esses processos de retirada de recursos foram conduzidos por um segmento quimicamente intensivo da esteira de produção, juntamente com a mecanização intensiva de retiradas ecológicas. Essas inovações químicas e tecnológicas intensificam o processo de retirada ou aceleram-se enquanto requerem redução de mão-de-obra, acelerando assim o potencial de acumulação de capital. Além disso, essa intensificação do processo de retirada ecológica acelera a desorganização ecológica, aumentando a destruição da natureza. Assim, há uma contradição entre a acumulação de capital e a destruição ecológica sob o capitalismo. As adições ecológicas consistem na emissão de poluentes no ecossistema. Ao longo do tempo a esteira de produção acelera, gera maiores quantidades de adições ecológicas e emite quantidades aumentadas de poluição. Essas adições ecológicas também produzem desorganização ecológica ao mudar a natureza e acelerar outras tendências ecologicamente destrutivas (por exemplo, a aceleração das mudanças climáticas em resposta às adições ecológicas). 


\begin{abstract}
Dentro dessa literatura, tanto o marxismo ecológico como a teoria da esteira da produção usam a teoria econômica e política para demonstrar que existe um conflito inerente ou contradição entre o capitalismo e a natureza. Esse conflito inerente significa que o capitalismo deve destruir a natureza para avançar (FOSTER, 2000; BURKETT, 2006) ${ }^{8}$. (LYNCH et al., 2013, p. 1001).
\end{abstract}

Portanto, equalizar o desenvolvimento sustentável com as principais premissas do capitalismo, que é a exploração da natureza e do trabalho humano é uma tarefa árdua e desafiadora, que só é possível partindo da identificação dos males ecológicos que habitualmente ocorrem ao nosso redor e também das forças políticas e econômicas que impulsionam esse processo, para que possam ser corrigidas.

\title{
2. DESENVOLVIMENTO ECONÔMICO E PRESERVAÇÃO DO MEIO AMBIENTE COMO POSTULADOS DE RESPONSABILIDADE CORPORATIVA
}

É bem verdade que a sociedade está marcada pelo processo de globalização, pelos crescentes avanços tecnológicos, pelo consumismo e pelo ritmo ditado pelo neoliberalismo. A vida humana, incluída nos cálculos e estratégias políticas da modernidade, exige o máximo de aproveitamento econômico e estatístico. Contudo, a conscientização de estabelecer limites alçou o meio ambiente ao status de bem jurídico. Com isso, a legislação ficou mais rígida no que se refere à responsabilidade por manter um meio ambiente saudável e equilibrado e às sanções civis e administrativas para os transgressores.

Com a percepção de uma série muito mais ampla de problemas sociais decorrentes da degradação ambiental, o mundo corporativo despertou para outros fatores tão relevantes quanto o lucro, o preço e a qualidade. Modificou-se a lógica do mercado e o tratamento do meio ambiente para estimular a responsabilidade social empresarial a incorporar a questão socioambiental na gestão.

Foram elaborados Códigos de Boas Práticas, especialmente sob a direção do Instituto Brasileiro de Governança Corporativa (IBGC) e da Comisão de Valores Mobiliários (CVM). Contudo, as normas voluntárias se mostraram inadequadas contra as falas dos diretores. Se elas podem produzir efeitos positivos quando aplicadas a pequenas e médias empresas, normas não legislativas para a Responsabilidade Social Corporativa carecem de eficácia diante das empresas multinacionais. O grande número de subsidiárias, inumeráveis sítios de fabricação ou de extração, de fato, dificultam o controle efetivo da controladora (holding companies) sobre as terceirizadas ao redor do mundo. Por exemplo, distâncias e lugares extremamente isolados podem ser as causas de um monitoramento superficial e dificultar a prevenção de acidentes ambientais, como aconteceu em 2010, quando a British Petroleum causou derramamento no Golfo do México. Essas dificuldades devem ser acrescentadas ao próprio interesse gerencial, que, neste caso, provavelmente desempenhou um papel importante na cobertura de

8 "Within that literature, ecological Marxism and the treadmill of production theory both use political economic theory to demonstrate that there is an inherent conflict or contradiction between capitalism and nature. That inherent conflict means that capitalism must destroy nature to advance (FOSTER, 2000; BURKETT, 2006)”. (Tradução nossa) 
avisos sobre problemas de engenharia das atividades extrativas e minimizou os riscos potenciais ${ }^{9}$.

Todavia, é preciso aqui diferenciar a origem dos conceitos de sustentabilidade e de responsabilidade social empresarial, porquanto ser socialmente responsável não atende verdadeiramente a dimensão socioambiental corporativa e é diferente de ser sustentável (BORGER, 2001).

A ideia de desenvolvimento sustentável iniciou com a preocupação com o meio ambiente e com a necessidade de envolvê-lo na dimensão econômica e social, como discorrido anteriormente. Já o conceito de responsabilidade social evoluiu de forma diferente, originando-se das questões éticas na relação empresa/sociedade e na filantropia empresarial. A excessiva autonomia dos negócios e o poder que estes exerciam na sociedade sem qualquer responsabilidade, causou preocupação pelas consequências sobre o meio ambiente, os trabalhadores, o abuso econômico e a concorrência desleal (BORGER, 2001).

Para compensar essas consequências, os empresários passaram a se envolver em atividades sociais em benefício da comunidade. Sobre essa realidade é que surgiu, na década de 1950, nos Estados Unidos e na Europa, a literatura sobre a responsabilidade social corporativa. Já o conceito de desenvolvimento sustentável passou a integrar a responsabilidade social empresarial a partir dos anos 1990 (BORGER, 2001). Hoje, está totalmente a ela integrado, preconizando a impossibilidade de haver crescimento econômico em longo prazo sem progresso social e sem cuidado com o meio ambiente.

Essespreceitos, enquantopartes integrantes das metas corporativas, especialmente as de desenvolvimento sustentável e conservação de recursos naturais, sustentam-se no tripé "sociedade, ambiente e economia" (Triple Bottom Line) ${ }^{10}$, sendo que nos dois últimos enfoques reside o conflito, a incompatibilidade.

Fazer negócios sustentáveis com a base e o topo da pirâmide significa, de um lado, criar modelos de negócios para atender às vastas camadas da população mundial excluídas do mercado, sem criar impactos adicionais sobre o meio ambiente, e, de outro, atuar sobre o superconsumo das classes de maior poder aquisitivo que, se hoje sustenta muitos negócios feitos dentro do modelo predador tradicional, no longo prazo é insustentável. (ALMEIDA, 2012, p. 31).

Cada vez mais os consumidores exigem responsabilidade e padrões de sustentabilidade das empresas pelos produtos que adquirem. Ora, isso afeta a competitividade da empresa por questões de custos. A implementação dos selos ou certificados que atestam a boa prática empresarial e uma produção socialmente correta e comprometida exige consultoria

\footnotetext{
9 Recentemente, um relatório interno da British Petroleum vazou para o Greenpeace e foi publicado pelo Financial Times. Contêm informações sobre uma regular subestimação de incidentes e avisos da equipe técnica pelos gerentes do British Petroleum, referentes ao local de extração nos EUA e no México. A notícia sobre o vazamento causou fortes reações de vários congressistas dos EUA. Ver Maeve McClenaghan e Lawrence Carter (2016), disponível em: https:// energydesk.greenpeace.org/2016/12/13/bp-leaked-report-sparks-concerns-safety/.

10 O tripé da sustentabilidade, chamado Triple Bottom Line ou três Ps: People, Planet, Profit destina-se a medir o desempenho financeiro, social e ambiental de uma empresa durante um período de tempo. People se refere ao tratamento do capital humano de uma empresa ou sociedade; Planet se refere ao capital natural de uma empresa ou sociedade e Profit se trata do lucro, do resultado econômico positivo de uma empresa (THE ECONOMIST, 2009).
} 
especializada, o que tem um custo elevadíssimo.

Da mesma forma as contratações públicas sustentáveis, ou seja, as licitações, que seria um meio de incentivar o desenvolvimento econômico mediante contratações administrativas que contemplassem o menor impacto ambiental, acabam não se perfectibilizando, pois o critério do menor custo financeiro é um obstáculo para a noção de custo ambiental, de modo que em vez de se optar pela proposta com "menor impacto negativo ao meio ambiente e, simultaneamente, os maiores benefícios econômicos e sociais", acaba prevalecendo tão somente o benefício econômico (FREITAS apud MORAIS; BRIDI, 2014, p. 299).

Muitas empresas têm demonstrado que não só são ecologicamente conscientes, mas ambientalmente corretas, porquanto estão verdadeiramente empenhadas em minimizar os impactos de suas atividades. Infelizmente, para outras, a sustentabilidade é slogan que disfarça a produção e reprodução de ações ambientalmente nocivas. Isso porque levam a cabo uma operação denominada greenwashing, "uma estratégia de comunicação muito utilizada pelas empresas para tornar mais aceitável uma atividade que é inevitavelmente perigosa tanto para o meio ambiente como para as pessoas"11 (NATALI, 2014, p. 15).

Em razão disso, muitas vezes é difícil para os cidadãos identificarem alguma diferença entre empresas genuinamente engajadas na causa ambiental e aquelas que estão "mascarando" atividades prejudiciais. Outras até mesmo promoveram mudanças por força de lei ou de decisão judicial, mas se apresentam como ecologicamente corretas enquanto seus advogados tentam reverter decisões nos tribunais ou aliados políticos, para cujas campanhas eleitorais contribuíram financeiramente, trabalham para destruir proteções ambientais. Os Estados também são instituições aptas a praticar atos lesivos ao meio ambiente, pois atuam em duas vias: ao permitir a instalação de empresas cujas atividades são prejudiciais ao meio ambiente e ao adotar políticas nocivas a este (PUCCI, 2012).

Essa situação preocupante ficou evidenciada recentemente no país com relatório apresentado pelo Grupo de Trabalho das Nações Unidas sobre Empresas e Direitos Humanos no Brasil. Especialistas independentes da ONU elaboraram o relatório após visita ao país em dezembro de 2015 e alertam para a fiscalização inadequada, poluição do meio ambiente e destruição de comunidades afetadas por grandes projetos e também para a influência indevida que o financiamento privado de campanhas eleitorais tem sobre os processos regulatórios do governo. Esses, entre outros aspectos, são as causas das violações dos direitos humanos perpetradas pelo setor empresarial brasileiro (ONU, 2016). O documento é um alerta para o cenário generalizado de infrações que envolvem os grandes empreendimentos e as falhas do Governo em monitorar as ações de empresas devido à "influência corporativa indevida sobre processos políticos e regulatórios" 12 , em razão do que a "capacidade do governo de monitorar operações de empresas pode, em alguns casos, ser afetada pelos processos de financiamento político e por lobby corporativo"13 (ONU, 2016, p. 13-14).

\footnotetext{
11 "Una estrategia de comunicación a menudo utilizada por las empresas para hacer más aceptable una actividad que es inevitablemente peligrosa tanto para el medio ambiente como para las personas" (Tradução nossa).

12 "Undue corporate influence on regulatory and policymaking processes" (Tradução nossa).

13 "Government's capability to oversee business operations may, in some cases, be affected by political financing processes and corporate lobbying”. (Tradução nossa)
} 
Ainda que esses fatores sejam apenas alguns dos exemplos que se propôs analisar, os quais constituem limitações ao pleno desenvolvimento sustentável, acabam também sendo causa da redução dos lucros e isso vai de encontro aos postulados do capitalismo, exigindo urgência na mudança desses paradigmas para que se possa vislumbrar uma nova sociedade ecologicamente sustentável e economicamente desenvolvida.

Não obstante a Constituição da República Federativa do Brasil, em seu artigo 225, impor ao poder público e a toda coletividade o dever de proteger e preservar o meio ambiente, assim como o advento da Lei ${ }^{\circ}$ 9.605/98 ser uma resposta às exigências de nossos tempos, mais especificamente a reivindicação pela responsabilização penal e administrativa das condutas lesivas ao meio ambiente, não se pode esquecer que também é postulação das sociedades hodiernas a possibilidade de desenvolvimento das atividades econômicas garantidas pela liberdade de mercado.

O modelo de desenvolvimento é o principal causador de grande parte das injustiças vivenciadas atualmente, dentre as quais as injustiças ambientais. $\mathrm{O}$ consumo dos recursos naturais não é igual para todos. Há cidadãos no mundo que consomem muito mais recursos do que outros. Daí não ser impossível deduzir que o nível de vida se mantém graças a um enorme desequilíbrio mundial (UNEP, 2011). Desse modo, o esgotamento ambiental se coloca como o limite para o avanço do capitalismo e isso está cada vez mais evidente diante do aumento contínuo do consumo acelerado de recursos da terra, excessivo nos países desenvolvidos, enquanto os demais, especialmente os mais pobres, “jamais retirarão suas cotas nesse 'fundo ambiental' do planeta” (BUCCI, 2013, p. 95).

Outros exemplos do desequilíbrio causado pelo capitalismo tóxico, predatório e desumanizado são as ações de corporações multinacionais nos países periféricos, cujos efeitos foram devastadores para o meio ambiente com graves violações de direitos humanos. Cita-se o impacto da indústria de óleo (Shell) na comunidade pesqueira do Delta do Níger; o vazamento de gases tóxicos (Union Carbide) em Bhopal, Índia; a poluição química (Conzic Rio Tinto Australia - CRA) na Ilha de Bougainville; o despejo de lixo tóxico na África do Sul (WILLIAMS, 2013), dentre muitos outros. Isso demonstra que a crise ambiental deve ser vista inclusive no contexto amplo de segurança global, posto que a segurança tradicional e as agendas econômicas ditam as prioridades políticas em relação às preocupações ambientais.

Diante desses argumentos, persiste mais celeuma: como atingir o equilíbrio entre conservação ambiental e desenvolvimento econômico? Acredita-se que uma pequena parte dessa resposta seja fomentar a coesão social na construção dos problemas ambientais, porque mesmo diante de todas as ações propostas para debelá-los nas últimas três décadas, eles atravessaram as portas do século XXI e se manifestam nos quintais de todas as nações, ainda que com maior ou menor grau de intensidade em cada uma.

A Sociologia Ambiental traz fortes pressupostos que auxiliam na compreensão dos efeitos que a crise socioambiental produz e produzirá nas sociedades humanas e sem perder de vista a ciência e a tecnologia como fortes aliadas, participa do desafio de imaginar um futuro sustentável. A proposta de equilíbrio entre conservação e 
desenvolvimento pressupõe uma mudança social, o que é possível através da educação ambiental que implica novas formas de se relacionar com os outros e com a natureza a partir de diferentes maneiras de pensar e de novas formas de organização política e econômica, insculpindo uma série de ações e práticas que levariam a essa nova sociedade ecologicamente sustentável e economicamente desenvolvida.

\section{A SOCIOLOGIA AMBIENTAL NA MEDIAÇÃO DA RELAÇÃO DESENVOLVIMENTO ECONÔMICO VERSUS DESENVOLVIMENTO SUSTENTÁVEL}

Ainda que toda a legislação constitucional e infraconstitucional ambiental represente um importante marco, os conflitos ambientais permanecem recorrentes e habituais, característicos de uma sociedade de risco ${ }^{14}$ (BECK, 2010). As empresas transgressoras são punidas com multas milionárias que não são pagas. Há evasão de responsabilidade porque estatutos foram produzidos para gerar a desresponsabilização. A regulamentação, quando existe, carece de estrutura e a fiscalização acaba sendo precária e insuficiente. Quando a regulamentação é mais dura, as corporações simplesmente evitam o controle social e movem suas forças produtivas para outro local, sendo forçoso reconhecer que o capitalismo global não pode ser efetivamente controlado por regulamentos estatais específicos.

Há, ainda, ausência de coesão popular, porque a sociedade geralmente não participa da tomada de decisões que podem afetá-la ambientalmente. E a participação é um importante princípio destacado pela Convenção de Aarhus ${ }^{15}$ nos seus artigos $2^{\underline{0}}$ e 6o- um dos projetos mais ambiciosos em matéria de democracia ambiental da ONU e importante instrumento de conotação global na pauta das tomadas de decisão que devem ter participação e conhecimento do público acerca de quaisquer procedimentos adotados em matéria ambiental (MAZZUOLI; AYALA, 2012).

A deterioração ambiental deve ser reconhecida como tal através de um processo de definição e construção social. Neste processo, o conhecimento científico de um determinado problema ambiental não se traduz necessariamente em ações para reverter o problema, o que confirma que este conhecimento, apesar de ser necessário para a tomada de decisões, não é suficiente.

De maneira geral, podem-se mencionar os seguintes fatores necessários para a construção bem sucedida de um problema ambiental, que de forma não linear John Hannigan (2009) propõe: atividades primárias, como aquelas a partir dos quais se

\footnotetext{
14 As bases da teoria da sociedade do risco são compreendidas como aquelas derivadas dos constantes avanços tecnológicos, científicos e econômicos que, ao mesmo tempo em que propiciam facilidades, ameaçam a vida humana. A sociedade altamente industrializada traz consigo, como produto da modernidade e da aliança entre capitalismo e desenvolvimento tecnológico, o medo, fruto do perigo das forças produtivas e criativas humanas. Em meio à política, o comportamento, a economia, a produção social, as ciências avançadas, as catástrofes ambientais, cada vez mais se desenvolve a lógica do risco.

15 A Convenção sobre Acesso à Informação, Participação do Público no Processo de Tomada de Decisão e Acesso à Justiça em Matéria de Ambiente foi adotada em Aarhus, Dinamarca, em 1998, por ocasião da IV Conferência Ministerial Ambiente para a Europa e entrou em vigor em 2001. Muito embora o Brasil não seja signatário da Convenção, há nela permissão para que possa aderi-la, como prevê o seu art. 19. (MAZZUOLI; AYALA, 2012, p. 309-310).
} 
nomeia os problemas e se estabelecem parâmetros para identificá-lo, direcionando a atenção pública e tratando de legitimar sua demanda; o estabelecimento de um foro central no qual se disputará, tanto em termos científicos como políticos, a validez e legitimidade dos argumentos esgrimidos pelas partes; o estabelecimento das "provas autênticas" do problema ambiental, as quais também passam pelos filtros científicos, morais e legais; o papel desempenhado pelos distintos atores políticos, científicos ou difusores do problema; por fim, as falhas potenciais e as condições de êxito na resolução do problema ambiental.

Aqui aparecem alguns fatores que devem ser levados em conta. O primeiro é ter autoridade científica para a validação dos seus argumentos" (HANNIGAN, 2009, p. 117). É virtualmente impossível para uma condição ambiental transformar-se em um problema sem a confirmação de dados provenientes das ciências físicas ou biológicas. O segundo é que devem surgir daqueles agentes que o converte em tal, os "populizadores" (HANNIGAN, 2009, p. 217) que em alguns casos são cientistas na sua função de divulgadores e em outros podem ser atores sociais diversos que podem estabelecer vínculos com o ambientalismo e a ciência: organizações governamentais, movimentos sociais ou grupos de interesse; afinal de contas, é preciso filtrar a situação ambiental na percepção de um grupo maior que respalde essa posição.

Em terceiro, um problema ambiental em construção tem que receber atenção dos meios de comunicação, "onde o argumento relevante é 'estruturado' como real e importante” (HANNIGAN, 2009, p. 118). O quarto fator é que o problema ambiental necessita ser "dramatizado em termos altamente simbólicos e visuais" (HANNIGAN, 2009, p. 118), a exemplo da crise mundial da água, do derretimento da calota polar, da redução da camada de ozônio. O quinto é a existência de incentivos econômicos para tomar medidas sobre um problema ambiental. Há uma concorrência pelovalor econômico que representam determinados recursos e são razões econômicas que determinam em muitos casos a possibilidade de que se alcance um acordo público para a resolução do problema. Por fim, o sexto fator, para que um problema ambiental encontre um canal de resolução, deve haver um "patrocinador institucional” (HANNIGAN, 2009, p. 118) que assegure a legitimidade e continuidade do processo de resolução.

Desta maneira, o emprego do termo crise socioambiental ajuda a compreender que: primeiro, as causas geradoras dos problemas ambientais são sempre sociais e segundo que as consequências dos mesmos acabam por recair sobre essa mesma sociedade. Os grandes problemas ambientais, característicos da sociedade de risco preconizada por Ulrich Beck (2010), têm causas antropogênicas relacionadas com o modelo econômico-industrial baseado na energia fossilizada e do carbono, em uma sociedade hiperconsumista e em um crescimento demográfico que aumenta as demandas sobre um planeta limitado.

A falta de controle social sobre os desenvolvimentos científicos situam a sociedade numa posição de alto risco no futuro, ao menos para a humanidade que se conhece na atualidade. Por isso, a coesão e o envolvimento social são cruciais. 
avaliação do risco são construídas socialmente. Estruturas políticas nacionais e estilos podem ser vistos como tendo mais a ver com as decisões sobre quais condições ambientais vão ser julgadas como arriscadas e merecedoras de ação, como a natureza do próprio argumento científico. Consequentemente os argumentos ambientais fundamentalmente completos podem ser desviados ou retardados, seja devido à colisão entre reguladores e cientistas ou por causa de pressão política de grupos de interesse, seja dentro ou em oposição à perspectiva ambientalista. (HANNIGAN, 2009, p. 176).

Por detrás de alguns discursos ecológicos é que subjaz uma sociedade justa e solidária e uma sociedade sustentável possível, sem maiores desigualdade sociais, originadas na crise ambiental e no perverso modelo liberal-economicista.

Frederick H. Buttel (1987, p. 465, traduçãonossa), apósexaminarodesenvolvimento da Sociologia Ambiental a partir da década de 1980, revê essa área de investigação empírica e propõe cinco áreas de discussão sociológica ambiental: (a) a nova "ecologia humana”, (b) as atitudes, os valores e os comportamentos ambientais, (c) o movimento ambiental, (d) o risco tecnológico e a avaliação de risco, e (e) a economia política do meio ambiente e a política ambiental.

Quanto à nova ecologia humana, Buttel (1987) se refere a esta como o núcleo da Sociologia Ambiental, cujos argumentos partem dos padrões básicos de organização social, moldados pelo imperativo das sociedades humanas em retirar da biosfera suas necessidades básicas de sobrevivência. Além disso, a nova ecologia humana, embora parta da ecologia humana clássica, elabora um argumento distinto: em vez de tender para o equilíbrio com os ambientes naturais de onde retiram sustento, as sociedades modernas tendem a exibir um padrão oposto, em que a degradação do meio ambiente e o esgotamento ambiental são exacerbados. De acordo com Buttel (1987), trabalhar a partir da nova ecologia humana é afirmar a relevância da Sociologia Ambiental genuína para os problemas prementes do mundo moderno, onde o antropocentrismo deve ser abandonado, assim como deve ser rejeitada a noção de que os humanos, devido à sua capacidade cultural e inovação tecnológica, estão isentos das leis ecológicas que governam a existência das espécies.

Com relação às atitudes, os valores e os comportamentos ambientais, Buttel (1987) destaca a pesquisa sobre essas categorias como uma das mais importantes áreas na subdisciplina. Ressalta a importância do exame da problemática socioestrutural, onde é investigada a existência de diferentes atitudes e crenças ambientais de segmentos diversos do público, além de outros fatores relacionados ao comportamento associado ao meio ambiente, a exemplo do descarte do lixo, da participação em programas de reciclagem, da conservação de energia doméstica etc., além das estruturas que induzem o comportamento ambiental (mensagens de mídia, recursos e incentivos).

O movimento ambiental é enfatizado a partir da compreensão mais teórica desse tipo de mobilização, especialmente os grupos ambientalistas locais ou especializados, tal como o movimento antinuclear, os movimentos de tecnologias apropriadas e os movimentos locais gerados diante doacúmulo de resíduos tóxicos e problemas ambientais a ele relacionados (BUTTEL, 1987, p. 476, tradução nossa). 
Foi justamente em razão dos movimentos ambientais que aumentou a preocupação com os riscos tecnológicos e a pressão crescente pela racionalização. $\mathrm{O}$ "estabelecimento do risco" combinou-se para conduzir ao "estabelecimento do perigo", cujo principal subconjunto é o "estabelecimento do risco ambiental" (BUTTEL, 1987, p. 480). É da análise do risco que partem os formuladores de políticas públicas.

Por fim, quanto à economia política do meio ambiente e a política ambiental, Buttel (1987) salienta a combinação das teorias neomarxista e neoweberiana como base para a literatura da economia ambiental-política nos Estados Unidos e na Europa. Nessa literatura emergente foram explorados dois problemas inter-relacionados: (a) os conflitos distributivos e as implicações da política ambiental, e (b) o alinhamento dos movimentos e grupos ambientais na política nacional, particularmente em relação ao trabalho e aos “novos movimentos sociais”. Buttel argumenta que o grau de centralização e o grau de autonomia do Estado em relação à sociedade civil, queé moldada pela estrutura de classes e pelos aspectos históricos do desenvolvimento político, é um componente importante da estrutura de oportunidades políticas dos movimentos ambientais. Outro componente vital da abordagem da economia política é a que compreende o ambientalismo como parte de um fenômeno mais amplo de "novos movimentos sociais" (BUTTEL, 1987, p. 482, tradução nossa).

Portanto, é tarefa da Sociologia Ambiental ajudar a compreender os efeitos que a crise socioambiental produz e produzirá nas sociedades humanas. Toda ciência deve ser descritiva, explicativa e preditiva. Embora reconhecendo a dificuldade de fazer previsões sobre o futuro da sociedade, a Sociologia Ambiental, em conjunto com outras ciências, participa do desafio de abrir novas janelas para as políticas públicas e imaginar um futuro sustentável.

Sabemos que é função das ciências sociais analisar causas e contextos, problematizar discursos, questionar propostas, aprofundar palavras. Por isso a Sociologia Ambiental revela ações presentes e posteriores ações que ajudam a construir a realidade social e a reconhecer o desenvolvimento tecnológico desenfreado como causa direta de boa parte dos problemas ecológicos vivenciados. Por outro lado, é também na ciência e na tecnologia que se encontra o conhecimento e as soluções práticas para um novo modelo de desenvolvimento sustentável.

Esse esforço certamente transcende definições técnicas, pois é necessário que além dos gestores públicos e dos agentes políticos, a sociedade civil esteja articulada e engajada numa proposta de garantia da sustentabilidade. Dessa maneira, tal fato demanda um empenho que vai além de normas, regras e padrões tecnológicos e tem como pilar estrutural o aprendizado social, a conscientização para ações focadas na formação de cidadãos culturalmente preparados para enfrentar a crise ambiental.

\section{CONCLUSÃO}

As alterações do meio ambiente são causas que não podem ser atribuídas unicamente ao capitalismo industrial. O consumo individual contribui para exacerbar a crise socioambiental. Toda e qualquer atividade humana tem potencial para causar 
danos à natureza. Assim, pode-se concluir que toda forma de desenvolvimento, predominantemente aquele baseado na quantidade de produção material, interfere de forma diferente no meio ambiente. As atividades industriais lideram o ranking de impacto ambiental por sua natureza. As mudanças climáticas, as migrações massivas, as epidemias, a crise da água têm se generalizado como consequência da rápida alteração dos ecossistemas e são apenas alguns sinais do que se sofrerá nos próximos decênios como desfecho para a exploração desenfreada de recursos naturais.

Evidencia-se a urgência de pensar com comprometimento sobre a crise ambiental planetária e na insuficiência da responsabilidade socioambiental empresarial para conter o esgotamento ambiental. Muito embora essa preocupação tenha se evidenciado nas mudanças promovidas na gestão empresarial, há muitos fatores que impedem a sua plena realização e o principal é a relação inconciliável entre os objetivos do capitalismo e os da conservação ambiental.

Buscou-se entender como esta preocupação vem sendo construída ao longo das últimas décadas, relacionando-a principalmente ao capitalismo industrial e ao consumo de massa, indissociáveis da globalização, porque está em constante simbiose com as politicas econômicas de governos e corporações.

A consciência do esgotamento dos recursos renováveis e não renováveis a partir dos anos 1970 foi o grande limitador ao desenvolvimento econômico, unindo-se a ele, a partir dos anos 1990, a incapacidade da biosfera para suportar mais poluição. Ainda que o meio ambiente seja um direito fundamental de todos os cidadãos, mesmo que a legislação tenha ampliado e agravado as cominações para os transgressores, embora muitas empresas estejam adotando estratégias de produção menos agressivas à natureza, estudos demonstram a insuficiência dessas ações. Isso porque existem interesses econômicos e políticos envolvidos, concentrados na maximização do lucro, na elevação da taxa de produção, na redução dos custos, no aumento das vendas e na criação de infinitas necessidades de consumo.

A correlação entre degradação do meio ambiente como resultado próprio do capitalismo e do desenvolvimento econômico permite compreender a Sociologia Ambiental como um importante instrumento de aprendizado e conscientização para conter o esgotamento ambiental. Depreendeu-se deste estudo a necessidade de impor limites ao avanço do capitalismo para administrar essa crise global. Constatou-se que a responsabilidade socioambiental empresarial, embora insuficiente para equilibrar o desenvolvimento econômico e o desenvolvimento sustentável, constitui-se importante instrumento para alcançá-lo, necessitando para isso superar a crise ética que atinge as políticas corporativas e estatais.

Por fim, essa discussão permitiu analisar criticamente as ações que Estados e corporações levam a cabo na causação da degradação do meio ambiente e na destruição de comunidades por ela afetadas, bem como a influência que a capacidade regulatória dos Estados sofre em razão de interesses políticos. Este estado de crise ética também perpassa todo o debate e pressupõe, para além de uma responsabilidade socioambiental das empresas, o aprendizado social focado na consciência ambiental e na construção social do ambiente. 
Mais do que consolidar o modelo de desenvolvimento sustentável, é preciso redefinir as bases da sociedade para que a relação homem/natureza concilie sustentabilidade ambiental e desenvolvimento, consequentemente, atingindo o almejado equilíbrio e conservação, bem como a igualdade na fruição de recursos. Assim, frente à exploração ilimitada de um planeta de recursos limitados, é necessário repensar o próprio conceito de bem-estar dependente de produtos de consumo, o fetichismo do $\mathrm{PIB}$, os interesses corporativos e políticos que convertem a sociedade em vítimas de uma economia opressiva e acelerada e que acabará condenando à extinção todas as formas de vida no planeta.

É através da Sociologia Ambiental que a questão ecológica se insere na agenda das ciências sociais, possibilitando um pensamento não só de preservação de espécies e ecossistemas, mas primordialmente de educação política e socioeconômica. Portanto, não se constitui apenas num projeto de melhor gestão empresarial, mas num projeto social, ético e político para a sustentabilidade.

\section{REFERÊNCIAS}

ALMEIDA, Fernando. Experiências empresariais em sustentabilidade - avanços, dificuldades e motivações de gestores e empresas. Rio de Janeiro: Elsevier, 2012.

ALVES, Liane; CORREA, Elisa; SANTOS, Priscilla et al. Quais são os principais selos ecológicos no mercado? Disponível em: < http://planetasustentavel.abril.com.br/ noticia/desenvolvimento/conteudo_298573.shtml >. Acesso em: 18 abr. 2017.

ARMADA Charles Alexandre Souza; VIEIRA, Ricardo Stanziola. A efetivação do direito ambiental no século XXI através de um estado transnacional ambiental. Revista de Direitos Fundamentais e Democracia, Curitiba, v. 15, n. 15, p. 148-166, jan./jun. 2014.

BARAK, Gregg. The Crimes of the Powerful and the Globalization of Crime. Revista Brasileira de Direito, 11(2): 104-114, jul./dez. 2015.

BECK, Ulrich. Sociedade de risco: rumo a uma outra modernidade. São Paulo: Ed. 34, 2010.

BEIRNE, Piers; SOUTH, Nigel. Issues in Green Criminology: confronting harms against environments, humanity and other animals. New York: Routledge, 2013.

BORGER, Fernanda Gabriela. Responsabilidade social: efeitos da atuação social na dinâmica empresarial. 2001. Tese (Doutorado) - Faculdade de Economia, Administração e Contabilidade, Universidade de São Paulo, São Paulo. 2001. Disponível em: < http:// www.teses.usp.br/teses/disponiveis/12/12139/tde-04022002-105347/pt-br.php >. Acesso em: 12 abr. 2017. 
BRASIL. Constituição da República Federativa do Brasil. Disponível em: < http:// www.planalto.gov.br/ccivil_03/constituicao/constituicaocompilado.htm >. Acesso em: 16 abr. 2017.

Lei no 9.605 de 12 de fevereiro de 1998. Disponível em: < http://www.planalto. gov.br/ccivil_03/leis/L9605.htm >. Acesso em: 16 abr. 2017.

BUCCI, Maria Paula Dallari. Fundamentos para uma teoria jurídica das políticas públicas. São Paulo: Saraiva, 2013.

BUDÓ, Marília de Nardin; COLOGNESE, Mariângela Matarazzo Fanfa, FRANÇA, Karine Agatha. O sofrimento animal como objeto da criminologia. In: X MOSTRA DE INICIAÇÃO CIENTÍFICA E EXTENSÃO COMUNITÁRIA E IX MOSTRA DE PESQUISA DE PÓS-GRADUAÇÃO DA IMED, 2016, Passo Fundo/RS. Anais. Passo Fundo/RS: Faculdade Meridional - IMED, 2016.

BUTTEL, Frederick H. New directions in environmental sociology. Annual Review of Sociology, v. 13, pp. 465-488, 1987. Disponível em: < http://www.annualreviews.org/doi/ abs/10.1146/annurev.so.13.080187.002341?journalCode=soc >. Acesso em: 17 out. 2017.

COMISSÃO MUNDIAL SOBRE MEIO AMBIENTE E DESENVOLVIMENTO. Nosso futuro comum. 2. ed. Rio de Janeiro: Editora da Fundação Getúlio Vargas, 1991.

CORPORATE REFORM COLLECTIVE. Fighting Corporate Abuse: Beyond Predatory Capitalism. London: Pluto Press, 2014.

DIAS, Genebaldo Freire. Pegada ecológica e sustentabilidade humana. São Paulo: Global Editora, 2007.

EON, Fábio. O que é responsabilidade social? 2015. Disponível em: < http://www. responsabilidadesocial.com/o-que-e-responsabilidade-social/ $\geq$. Acesso em: 18 abr. 2017.

FRIEDMAN, Milton. Capitalism and freedom. Chicago: Chicago University Press, 1962.

GLENN, Patrick H. A transnational concept of Law. In: CANE, Peter; TUSHNET, Mark. Oxford Handbook of Legal Studies. Oxford: Oxford University Press, 2005.

HANNIGAN, John. Sociologia Ambiental. Tradução de Annahid Burnett. Petrópolis, (RJ): Vozes, 2009. 
HARVEY, David. Seventeen contradictions and the end of capitalism. London: Profile Books, 2015.

HICKEL, Jason. To deal with climate change we need a new financial system. The Guardian, United Kingdom, 5 nov. 2016. Disponível em: < https://www.theguardian. com/global-development-professionals-network/2016/nov/o5/how-a-new-moneysystem-could-help-stop-climate-change >. Acesso em: 18 abr. 2017.

LATOUCHE, Serge. Pequeno tratado do decrescimento sereno. Tradução de Cláudia Berliner. São Paulo: Martins Fontes, 2009.

LYNCH, Michael J.; LONG, Michael A.; BARRETT, Kimberly L., et al. Is it a Crime to Produce Ecological Disorganization? Why Green Criminology and Political Economy Matter in the Analysis of Global Ecological Harms. The British Journal of criminology. 2013, 53, pp. 997-1016. Disponível em: < http://bjc.oxfordjournals.org/content/53/6/997. full.pdf+html?sid=oc96a303-93de-4abf-85c5-b4cf8897dd5o >. Acesso em: 17 abr. 2017.

MCCLENAGHAN, Maeve; CARTER, Lawrence. Leaked report reveals BP safety failures as it heads back to Gulf of Mexico. Energy Desk Greenpeace, 13 dez. 2016. Disponível em: $<\quad$ https://energydesk.greenpeace.org/2016/12/13/bp-leaked-report-sparks-concernssafety/ >. Acesso em: 17 abr. 2017.

MARX, Karl. O capital - crítica da economia política. Volume I. Livro Primeiro. O processo de produção do capital. São Paulo: Nova Cultural, 1996.

MAZZUOLI, Valerio de Oliveira; AYALA, Patryck de Araújo. Cooperação internacional para a preservação do meio ambiente: o direito brasileiro e a Convenção de Aarhus. Revista Direito GV, vol. 8, n. 1, p. 297-328. São Paulo jan./jun. 2012. Disponível em: < http://www.scielo.br/scielo.php?script=sci_arttext\&pid=S1808-24322012000100012 >. Acesso em: 16 abr. 2017.

MORAIS, Fausto Santos de; BRIDI, Janaína Hennig. As contratações sustentáveis e o problema do julgamento objetivo. In: BOFF, Salete Oro; ESPINDOLA, Angela Araujo da; TRINDADE, André Karam. Direito, democracia e sustentabilidade: anuário do programa de pós-graduação Stricto Sensu em Direito da Faculdade Meridional. Passo Fundo: IMED Editora, 2014.

NATALI, Lorenzo. Criminology, victimización medioambiental y social harm - El caso de Huelva (España). Revista Crítica Penal y Poder. OSPDH, n. 7, p. 5-34, set. 2014.

ORGANIZAÇÃO DAS NAÇÕES UNIDAS - ONU. A ONU e o meio ambiente. 2016. Disponível em: < https://nacoesunidas.org/acao/meio-ambiente/ >. Acesso em: 16 abr. 2017. 
. Fatos sobre desastres. Rio de Janeiro, 2012. Disponível em: < http://www.onu. org.br/riozo/desastres.pdf >. Acesso em: 16 abr. 2017.

Our common future. Report of the World Commission on Environment and Development. 1987. Disponível em: < http://www.onu.org.br/rio2o/img/2012/o1/ N8718467.pdf >. Acesso em: 16 abr. 2017.

Report of the Working Group on the issue of human rights and transnational corporations and other business enterprises on its mission to Brazil. Brasil: 2015. Disponível em: < https://documents-dds-ny.un.org/doc/UNDOC/ GEN/G16/o96/43/PDF/G16o9643.pdAcf?OpenElement >. Acesso em: 17 abr. 2017.

PUCCI, Rafael Diniz. Criminalidade ambiental transnacional. Desafios para a sua regulação jurídica. 2012. 203 p. Tese (Doutorado) - Departamento de Filosofia e Teoria Geral do Direito, Universidade de São Paulo, São Paulo, 2012. Disponível em: < http:// www.teses.usp.br/teses/disponiveis/2/2139/tde-27082013-115114/pt-br.php. >. Acesso em: 18 abr. 2017.

SARLET, Ingo Wolfgang; FENSTERSEIFER Tiago. Direito constitucional ambiental: estudos sobre a Constituição, os Direitos Fundamentais e a Proteção do Ambiente. São Paulo: Revista dos Tribunais, 2011.

SCHNAIBERG, Allan. The Environment: From Surplus to Scarcity. New York: Oxford University Press, 1980.

SEN, Amartya. Desenvolvimento como liberdade. Tradução de Laura Teixeira Motta. São Paulo: Companhia das Letras, 2010.

Triple Bottom Line. The Economist, 17 nov. 2009. Retrieved 14 August 2014. Disponível em: < http://www.economist.com/node/14301663 >. Acesso em: 18 abr. 2017.

UNITED NATIONS ENVIRONMENT PROGRAMME - UNEP. Decoupling natural resource use and environmental impacts from economic growth. Report of the UNEPWorking Groupon Decoupling to the International ResourcePanel, 2011. Disponível em: < http://www.onu.org.br/riozo/img/2012/o1/DecouplingENGSummary-1.pdf >. Acesso em: 16 abr. 2017.

WILLIAMS, Christopher. Environmental victims - new risks, new injustices. New York: Earthscan, 2013. 